Rel at i onshi $p$ bet ween upper - body st rengt $h$ and bat swi ng speed in hi gh- school basebal I pl ayers

\begin{tabular}{|c|c|}
\hline 著者 & M yaguchi Kazuyoshi, Demur a Shi ni chi \\
\hline $\begin{array}{l}\text { j our nal or } \\
\text { publ i cat i on ti t l e }\end{array}$ & Journal of Strengt $h$ and Condi ti oni ng Research \\
\hline vol une & 26 \\
\hline number & 7 \\
\hline page $r$ ange & 1786- 1791 \\
\hline year & 2012-07- 01 \\
\hline URL & ht t p: //hdl . handl e. net /2297/31986 \\
\hline
\end{tabular}




\title{
Relationship between upper-body strength and bat swing speed in high school baseball players
}

\author{
Running head: Bat swing and bench power
}

\author{
Kazuyoshi Miyaguchi \\ Ishikawa Prefectural University \\ Suematsu 1-308, Nonoichimachi, Ishikawa 921-8836, Japan
}

\begin{abstract}
Shinich Demura
Kanazawa University Graduate School of Natural Science \& Technology,

Kakuma, Kanazawa, Ishikawa 920-1164, Japan
\end{abstract}

Address correspondence to:

Kazuyoshi Miyaguchi

Ishikawa Prefectural University

Suematsu 1-308, Nonoichimachi, Ishikawa 921-8836, Japan

Phone: (+81) 076-227-7220, Fax: (+81) 076-227-7410

e-mail: kazu1060@lapis.plala.or.jp 
Relationship between upper-body strength and bat swing speed in high school baseball players

Running head: Bat swing and bench power 
Bat swing and bench power

\section{ABSTRACT}

This study aimed to clarify the relationship between upper-body strength and bat swing speed in high school baseball players and to examine physical characteristics of home run hitters (sluggers). The subjects were 30 male high school baseball players with national tournament experience at Koshien Stadium. Bat swing speed exerted by full effort was measured with a microwave-type speed measuring instrument. One repetition maximum (1 RM) of a bench press, bench press power (bench power) using a light load (30kg), and isokinetic chest press $(0.4 \mathrm{~m} / \mathrm{s}, 0.8 \mathrm{~m} / \mathrm{s}, 1.2 \mathrm{~m} / \mathrm{s})$ were measured as upper-body strength. The relationships between bat swing speed and upper-body strength values were examined. Additionally, the t-test was used to reveal the mean differences between 14 home run hitters (Group-A) and 16 mediocre hitters (Group-B) for each measurement value. The bat swing speed showed significant and middle correlations with the 1RM bench press (1RM BP) $(r=0.59)$, bench power $(0.41)$, and isokinetic chest press $(0.48-0.55)$. Group-A had significantly higher values in bench power and isokinetic chest press (high-speed) per kilogram of body weight than Group-B. The swing speed showed significant correlations ( $\mathrm{r}=0.62)$ with $1 \mathrm{RM}$ bench press in Group-B, but not in Group-A. In conclusion, to improve the hitting power of high school baseball players, it may also be important to develop bench power with light loads in addition to 1RM BP.

Key words: bat swing speed, 1RM bench press, home run hitter, bench power 
Bat swing and bench power

\section{INTRODUCTION}

In today's baseball, muscular power has been more demanded in comparison with the past because of improvements in equipment or the expansion of baseball stadiums. Therefore, muscle (resistance) training is important for baseball players in addition to batting skill improvement. Recently, also in high-school baseball, which is a cornerstone of college and professional baseball, the ratio of muscle training included in training programs has increased. The use of the metal bat is especially accepted in high school baseball championships. When using a wooden bat, the ball is powerfully hit only when on the bat strikes the "sweet spot." However, when using a metal bat, if swinging fast in spite of missing a little of the sweet spot, players can hit the ball powerfully. Also in previous studies $(1,4,5)$, it was reported that increasing bat swing speed is important for players to become successful long-ball hitters.

When increasing bat swing speed, the following becomes possible: longer decision time, decreased swing time (5), and increased ball velocity (9). Therefore, hitters actively perform muscle training to increase swing speed. However, it is often performed without clear knowledge of the method and the training effects.

The bench press is a typical training program for the upper body, and one repetition maximum (1 RM) of a bench press is an index of muscular power development. Hence, the bench press is frequently used by power athletes like baseball players aiming to improve performance in spite of having the differences with actual movement or agonist muscle (8). 
Bat swing and bench power

It is necessary for hitters to swing at a pitch quickly with a light 900 gram bat. Hence, the following hypothesis was set in this study: "sluggers (power hitters) who can hit home runs are superior in not only $1 \mathrm{RM} \mathrm{BP}$, but also the ability of muscle power exertion to light loads."

Until now, the physical fitness of baseball players has mainly been studied by examining professional or collegiate baseball players. There have been few studies which examined high school baseball players with remarkable technical or physical growth. In addition, the physical characteristics of home run hitters have been little examined. Hence, to get data on training regimens aimed at improving power hitting, this study aimed to examine the relationship between upper-body strength and bat swing speed in addition to the physical characteristics of high school home run hitters.

\section{METHODS}

\section{Approach to the problem}

Until now, there have been many reports that muscular strength and leg power are important for increasing batted-ball speed $(2,13,14,15,16)$. Batting is a sequence of coordinated muscle activity, beginning with the hip, followed by the trunk, and terminating with the arms. Power in the swing is initiated in the hip, and therefore exercises that emphasize such strength development are indicated (12). 
Bat swing and bench power

However, in this study, we focused on the upper-body strength which is related directly to the bat swing movement, and examined the relationship between upper-body strength and bat swing speed. Similarly, we examined the relationship between bat swing speed and bench power and isokinetic chest press which require the same movements as the bench press in spite of different types of muscle contraction. In addition, the upper-body strength measurements and power were also converted into variables per kilogram of body weight (relative values) because the subjects were high school players with remarkable physical growth.

\section{Subjects}

The subjects were 30 male high school baseball players (mean age $16.6 \pm 0.5 \mathrm{yr}$, mean height $171.5 \pm 3.8 \mathrm{~cm}$, and mean weight $65.0 \pm 6.2 \mathrm{~kg}$ ) with national tournament experience at Koshien Stadium. They all had competitive experience of more than five years. All subjects were injury-free at the time of testing. The team practiced 6 days a week for 3 hours a day. All players experienced previously resistance training. Fourteen players with home run experience in official matches were assumed to be home run hitters or sluggers (Group A), and the other sixteen players were assumed to be mediocre hitters (Group B). Appropriate Institutional Review Board approval and informed consent was obtained. All athletes were 
fully informed of all possible risks and stresses associated with the project and signed consent forms prior to participation.

\section{Measurement of bat swing speed}

A standard metal bat $(83.0 \mathrm{~cm}$ in length and $907 \mathrm{~g}$ in weight; Mizuno) was used for all swings. Before measuring the bat swing speed, all subjects underwent their regular warm-up and stretching routine. The subjects performed a practice swing that simulated practical situations three times with maximal effort. Bat swing speed was measured by using a microwave-type speed measuring instrument (RED EYES POCKET: PRGR). Measurements were carried out three times, and the best record was adopted for analysis. The test-retest reliability (intraclass correlation coefficient [ICC]) between swing trials was very high (0.92).

$$
+++<\text { Figure } 1>\text { near here }+++
$$

\section{Measurement of muscle strength and power}

1) $1 \mathrm{RM}$ bench press

Bench press capacity was evaluated by the maximum lifts (maximum one-repetition of bench press: $1 \mathrm{RM}$ ) within one week from the measurement of bat swing speed.

2) Isokinetic chest press

Isokinetic chest press with 3 speed patterns (low speed: $0.4 \mathrm{~m} / \mathrm{s}$, middle speed: $0.8 \mathrm{~m} / \mathrm{s}$, high speed: $1.2 \mathrm{~m} / \mathrm{s}$ ) were measured by chest force (Takei, Japan) 
3) Bench power test (Speed Bench Press Test)

A bench power test was used to evaluate upper-body muscle power for each subject. The load of the barbell was unified at $30 \mathrm{~kg}$. This was $37.5 \%$ of the average of 1RM BP. After the barbell touched the chest, subjects were instructed to power the barbell upwards as fast as possible until their arms reached full extension. Subjects performed 2 sets using this technique. Peak velocity (PV) and peak power (PP) values were recorded using the Fitrodyne device (Fitrodyne, Bratislava, Slovak Republic) (Figure 2). The larger value was used for analysis. The test-retest reliability (ICC) between trials was high (0.79).

$$
+++<\text { Figure } 2>\text { near here }+++
$$

\section{Statistical Analysis}

The reliability of measurement values exerted by various tests was examined by ICC. The relationships between bat swing speed and each measurement with 2 conditions (absolute values and relative values) were examined by using Pearson's correlation coefficient. A paired t-test was used to reveal the mean differences between Group-A and Group-B for physical characteristics and parameters, and effect size (ES) was calculated to examine the size of the mean differences. A statistical significance was set at $p \leq 0.05$.

\section{RESULTS}

Table 1 shows physical characteristics and measurements of each subject. The coefficient 
of variations of bench power (CV: 0.21$)$ and isokinetic chest press $[1.2 \mathrm{~m} / \mathrm{s}](0.17)$ were larger than the other measurement items.

$$
+++ \text { Table } 1>\text { near here }+++
$$

Table 2 shows correlations between bat swing speed and each measurement. In the absolute values, the bat swing speed showed significant and middle correlations with the 1 $\mathrm{RM} \operatorname{BP}(\mathrm{r}=0.59)$, isokinetic chest press $[1.2 \mathrm{~m} / \mathrm{s}, 0.8 \mathrm{~m} / \mathrm{s}, 0.4 \mathrm{~m} / \mathrm{s}](0.55,0.51,0.48)$, and bench power $(0.41)$. On the other hand, in the relative values, the bat swing speed showed significant and low correlations only with isokinetic chest press [1.2m/s] (0.39). Although significant and middle correlations (0.59) were found in the absolute values between 1RM BP and bench power, this correlation was not found in the relative values.

$$
+++<\text { Table } 2>\text { near here } \quad+++
$$

Table 3 shows the results of the t-test to display the mean differences between Group-A and Group-B for evaluation parameters in terms of relative values. The swing speed, bench power, and isokinetic chest press $(1.2 \mathrm{~m} / \mathrm{s})$ under per kilogram of body weight showed significantly larger values in Group-A than in Group-B. As for the bench press, there were insignificant differences between both groups.

$$
+++<\text { Table } 3>\text { near here }+++
$$

Figure 3 shows the correlations between bat swing speed and 1RM bench press by groups. The swing speed showed significant and moderate correlations $(r=0.62)$ with $1 \mathrm{RM}$ 
bench press in Group-B, but not in Group-A.

$$
\text { +++ < Figure } 3>\text { near here }+++
$$

\section{DISCUSSION}

Traditional heavy strength training, including the bench press, has frequently been performed with heavy loads (80-90\% of the maximum) and few repetitions (4-8 RM). It has been reported that this produces an optimal strength increase (3) and enhances power and movement speed more than strength training with light loads $(10,11)$. The $1 \mathrm{RM}$ BP test is the maximal strength test of choice for most strength and conditioning professionals because it does not require expensive equipment and reflects the kind of dynamic ability necessary in sport. However, in this study, 1RM BP showed only significant and low correlations $(\mathrm{r}=0.39)$ with bench power with light loads in the relative values. Different factors may contribute to both measurements.

1RM BP (CV: 0.10), bench power (0.21) and Isokinetic chest press (0.15-0.17) involve similar movements, and the agonist muscles are also considered to be almost the same. However, it may be noted that coefficient of variations (CV) were different. The measurements of muscle strength and power of each subject may be considerably different by the muscular contraction type.

Hence, it is possible that measuring only traditional 1RM BP cannot evaluate muscle power of power hitters sufficiently when evaluating the upper-body strength of baseball 
players. When considering the contribution to the bat swing speed, it will be important to evaluate muscle power exertion with light-loads or with fast repetitions.

A significant difference in height was not found between Group-A $(172.6 \pm 3.1 \mathrm{~cm})$ and Group-B $(170.5 \pm 4.3 \mathrm{~cm})(\mathrm{t}=1.50, \mathrm{p}>0.05)$. However, Group-A $(68.8 \pm 4.9 \mathrm{~kg})$ was heavier than Group-B $(61.7 \pm 5.2 \mathrm{~kg})(\mathrm{t}=3.85, \mathrm{p}<0.01)$. For this reason, the relationships between bat swing speed and each measurement in the relative values as well as the absolute values were examined.

Bat swing speed showed significant correlations with the 1 RM BP, isokinetic chest press, and bench power in the absolute values, but only did so with isokinetic chest press $(1.2 \mathrm{~m} / \mathrm{s})$ in the relative values. In fact, the movement under isokinetic muscular contraction is not found in an actual exercise routine. However, it was clarified that hard hitters are superior in muscle power exertion under high-speed isokinetic conditions. Although controlling and monitoring velocity during strength testing requires sophisticated equipment, the resulting strength scores are more meaningfully related to a hitter's ability than static strength measurements or maximum lifts.

There were significant differences of about $10 \mathrm{~kg}$ between Group-A $(85.1 \pm 5.1 \mathrm{~kg})$ and Group-B $(76.1 \pm 7.9 \mathrm{~kg})$ in $1 \mathrm{RM}$ BP in the absolute values, but not in the relative values. On the other hand, in the relative bench power values, there was a significant and marked difference (ES: 4.75) between Group-A (12.8W) and Group-B (11.0W). Therefore, it is 
Bat swing and bench power

suggested that hard hitters who can hit a home run are superior in not only absolute muscular strength, but also the ability of muscle power exertion to light weight per kilogram of body weight.

This may also be supported by the fact that a significant difference was found in the relative chest press under the isokinetic high-speed condition. This suggests that the ability to exert high speed muscle power is important for hitting home runs. Figure 3 shows the above-mentioned clearly. The swing speed showed significant and moderate correlations ( $\mathrm{r}=0.62)$ with $1 \mathrm{RM}$ bench press in Group-B, but not in Group-A.

In conclusion, actively using the bench-press in a workout routine is essential for high school baseball players to improve hitting power. In fact, it was recently reported that bench press capacity (1RM BP) relates to the development of the early power output when using Stretch-Shortening Cycle (SSC) in the upper limbs (8).

However, a few studies have shown that greater improvements in maximal power output using lighter loads $(30-40 \%$ of $1 \mathrm{RM})(7,17)$. In this study, it was suggested that hard hitters who can hit a home run are superior in not only absolute muscular strength, but also the ability of muscle power exertion to light weight. Jones et al. (6) divided NCAA Division I baseball players into two groups and reported that the low-resistance group displayed a strong trend for larger increases in peak power and peak velocity at testing resistances specific to training resistances (i.e., 30 and 50\% 1RM) than the high-resistance group. Both of the 
training groups intended to maximally accelerate each repetition during the concentric phase (IMCA).

Therefore, it may be important for power hitters to improve bench power using light-loads in addition to $1 \mathrm{RM} B P$.

\section{PRACTICAL APPLICATIONS}

1RM BP has been used as a muscular strength index of upper body strength in baseball players. When muscular strength level is low, it is essential to enhance 1RM BP for strengthening major muscles for baseball. However, if players have accumulated considerable strength training experience, not only enhancement of 1RM BP but also bench presses with light-loads or isokinetic strength with fast repetitions would be important for hitting a ball hard. Baseball players and strength and conditioning coaches should make up a training plan that considers the above to foster batter's power hitting ability. The present results support the use of a combination of heavier training loads and IMCA with light loads to increase 1RM BP of high school baseball players.

\section{REFERENCES}

1. Adair, RK. The Physics of Baseball (3rd ed.). New York: Harper Publishers, 2002.

2. Basile, R, Otto, RM, and Wygand, JW. The relationship between physical and 
physiological performance measures and baseball performance measures. Med Sci Sports Exerc 39(Suppl.): S214, 2007.

3. Berger, R. Optimum repetitions for the development of strength. Res Quart 33: 334-339, 1962.

4. DeRenne, C, Buxton, BP, Hetzler, RK, and Ho, KW. Effects of weighted bat implement training on bat swing velocity. J Strength Cond Res 9: 247-250. 1995.

5. Hay, JG. Baseball. In: Biomechanics of Sports Technique (3rd ed.). Englewood Cliffs, NJ: Prentice-Hall, Inc., 1985. pp. 188-213.

6. Jones, K, Bishop, P, Hunter, G and Fleisig, G. The Effects of Varying Resistance-Training Loads on Intermediate- and High-Velocity-Specific, J Strength Cond Res 15: 349-356, 2001.

7. Kaneko, M, Fuchimoto, T, Toji, H, and SUEI, K. Training effect of different loads on the force-velocity relationship and mechanical power output in human muscle. Scand. J. Sports Sci. 5: 50-55. 1983.

8. Miyaguchi, K, and Demura, S. Muscle power output properties using the stretch-shortening cycle of the upper limb and their relationships with a one-repetition maximum bench press. $\mathrm{J}$ Physiol Anthropol. 25(3):239-245, 2006.

9. Race, DE. A cinematographic and mechanical analysis of the external movements involved in hitting a baseball effectively. Res Q 32: 394-404, 1961. 
10. Schmidtbleicher, D, and Haralambie, G. Changes in contractile properties of muscle sfter strength training in man. Eur J Appl Physiol 46: 221-229, 1981.

11. Schmidtbleicher, D, and Buehrle, M. Neuronal adaptations and increase of cross-sectional area studying different strength training methods. In Johnson G. (ed) Biomechanics X-B Vol 6-B Human Kinetics Publishers Champaign IL USA 615-620, 1987.

12. Shaffer, B, Jobe, FW, Pink, M, and Perry, J. Baseball batting. An electromyographic study, Clin Orthop Relat Res. 292: 285-293, 1993.

13. Spaniol, FJ. Physiological predictors of bat speed and throwing velocity in adolescent baseball players. J Strength Cond Res 16: 16, 2002.

14. Spaniol, FJ, Bonnette, R, Melrose, D, and Bohling, M. Physiological predictors of bat speed and batted-ball velocity in NCAA Division I baseball players. J Strength Cond Res 20: $185,2006$.

15. Szymanski, DJ, Albert, JM, Reed, JG, and Szymanski, JM. Physiological predictors of sport-specific skills of Division I collegiate baseball players. In: Proceedings of the 36th Annual Meeting of the SEACSM. D. Torok, ed. Birmingham, AL: Southeastern Chapter of the American College of Sports Medicine, 2008. pp. 27.

16. Szymanski, JM, Szymanski, DJ, Albert, JM, Hemperley, DL, Hsu, HS, Moore, RM, Potts, JD, Reed, JG, Turner, JE, Walker, JP, and Winstead, RC. Relationship between physiological characteristics and baseball-specific variables of high school baseball players. 
J Strength Cond Res 22: 110-111, 2008.

17. Wilson, GJ, Newton, RU, Murphy, AJ, and Humphries, BJ. The optimal training load for the development of dynamic athletic performance. Med. Sci. Sports Exerc. 25: 1279-1286. 1993. 
Bat swing and bench power

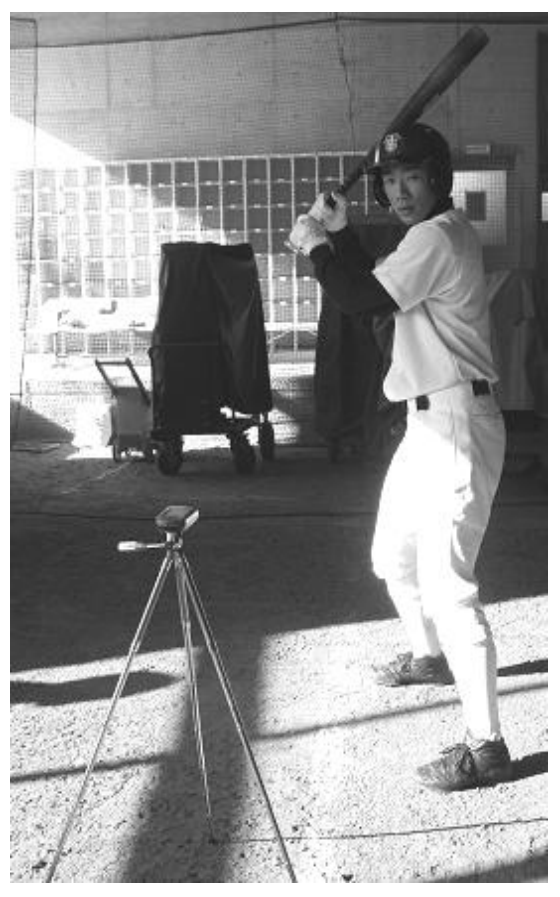

Figure 1 Measurement of batswing speed using a microwave -type speed measuring instrument 


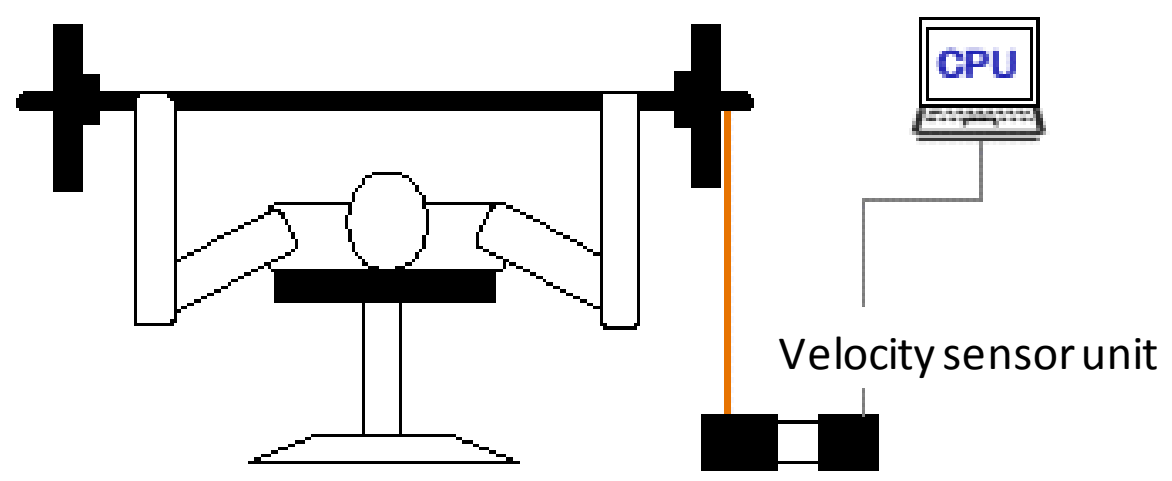

Figure 2 Bench power test using the Fitrodyne device (Bratislava, Slovak Republic) 
Bat swing and bench power

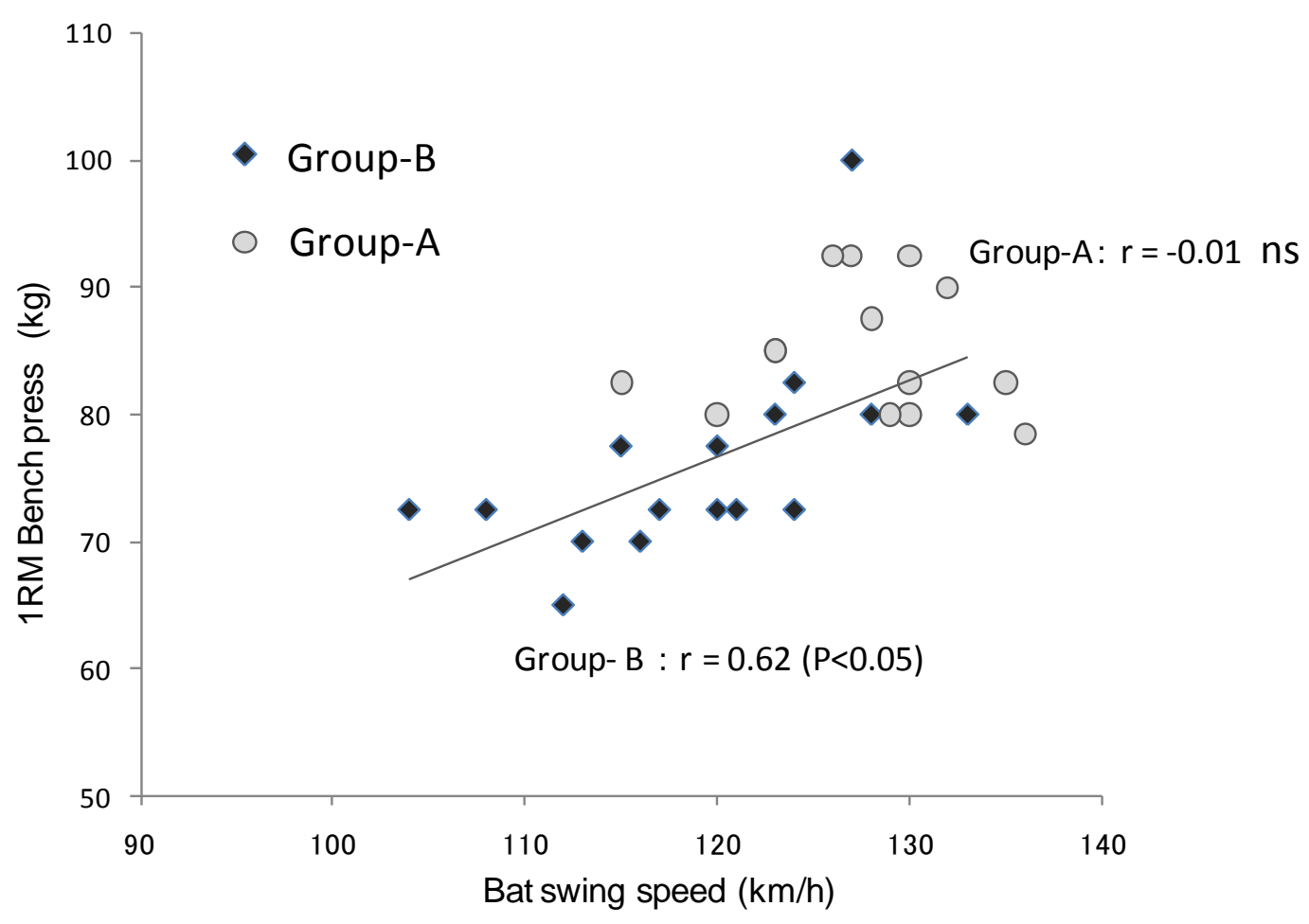

Figure 3 Correlation s between bat swing speed and 1RM bench press Group-A: home run hitters Group-B: mediocre hitters ns: no significant 
Bat swing and bench power

Table 1 Physical characteristics and evaluation parameters

\begin{tabular}{llccccc}
\hline & & Mean & SD & Min & Max & CV \\
\hline Height & $\mathrm{cm}$ & 171.5 & 3.8 & 162 & 179 & 0.02 \\
Weight & $\mathrm{kg}$ & 65.0 & 6.2 & 52.8 & 79.5 & 0.09 \\
Bat swig speed & $\mathrm{km} / \mathrm{h}$ & 123.0 & 7.9 & 104 & 136 & 0.06 \\
1 RM bench press & $\mathrm{kg}$ & 80.3 & 8.0 & 65 & 100 & 0.10 \\
Bench power & $\mathrm{W}$ & 767.8 & 160.8 & 451 & 1207 & 0.21 \\
lsokinetic chest press $(0.4 \mathrm{~m} / \mathrm{s})$ & $\mathrm{W}$ & 221.3 & 32.3 & 172 & 299 & 0.15 \\
lsokinetic chest press $(0.8 \mathrm{~m} / \mathrm{s})$ & $\mathrm{W}$ & 358.5 & 54.6 & 258 & 497 & 0.15 \\
lsokinetic chest press $(1.2 \mathrm{~m} / \mathrm{s})$ & $\mathrm{W}$ & 434.4 & 73.8 & 295 & 625 & 0.17 \\
\hline
\end{tabular}

$\mathrm{CV}$ : coefficient of variations 
Table 2 Correlations between bat swing speed and each measurement

\begin{tabular}{|l|c|c|c|c|c|}
\hline & $\begin{array}{c}1 \mathrm{RM} \\
\text { bench }\end{array}$ & $\begin{array}{c}\text { Bench } \\
\text { power }\end{array}$ & \multicolumn{3}{|c|}{$\begin{array}{c}\text { Is okinetic chest press } \\
(0.4 \mathrm{~m} / \mathrm{s})\end{array}$} \\
\hline & $.588^{*}$ & $.408^{*}$ & $.476^{*}$ & $.509^{*}$ & $.551^{*}$ \\
\hline Absolute value & .213 & .256 & .228 & .292 & $.394^{*}$ \\
\hline $\begin{array}{l}\text { Value per kilogram of } \\
\text { body weight }\end{array}$ & $.213)$ \\
\hline
\end{tabular}

${ }^{*}: \mathrm{P}<0.05$ 
Table 3 Results of a t-test to reveal mean differences between Group-A and Group-B for evaluation parameters in the value per kilogram of body weight

\begin{tabular}{|c|c|c|c|c|c|c|c|}
\hline & & \multicolumn{2}{|c|}{ Group-A $(n=14)$} & \multicolumn{2}{|c|}{ Group-B $(n=16)$} & \multirow[b]{2}{*}{$t$-value } & \multirow[b]{2}{*}{ ES } \\
\hline & & Mean & SD & Mean & SD & & \\
\hline Bat swing speed & $\mathrm{km} / \mathrm{h}$ & 127.43 & 5.72 & 119.06 & 7.63 & $3.36 *$ & 6.28 \\
\hline $1 \mathrm{RM}$ bench press & $\mathrm{kg}$ & 1.24 & 0.08 & 1.24 & 0.11 & 0.08 & 0.16 \\
\hline Bench power & W & 12.80 & 2.19 & 10.95 & 1.80 & 2.54 * & 4.75 \\
\hline Isokinetic chest press $(0.4 \mathrm{~m} / \mathrm{s})$ & W & 3.52 & 0.43 & 3.39 & 0.33 & 0.89 & 1.67 \\
\hline Isokinetic chest press $(0.8 \mathrm{~m} / \mathrm{s})$ & W & 5.79 & 0.71 & 5.41 & 0.57 & 1.62 & 3.03 \\
\hline Isokinetic chest press $(1.2 \mathrm{~m} / \mathrm{s})$ & W & 7.19 & 0.95 & 6.38 & 0.65 & 2.76 * & 5.16 \\
\hline
\end{tabular}

ES: effect size *: $P<0.05$ 
Table 3 Results of a t-test to reveal mean differences between Group-A and Group-B

\begin{tabular}{|c|c|c|c|c|c|c|c|}
\hline & \multicolumn{3}{|c|}{ Group-A $(n=14)$} & \multicolumn{2}{|c|}{ Group-B $(n=16)$} & \multirow{2}{*}{\multicolumn{2}{|c|}{$t$-value }} \\
\hline & & Mean & SD & Mean & SD & & \\
\hline Bat swing speed & $\mathrm{km} / \mathrm{h}$ & 127.43 & 5.72 & 119.06 & 7.63 & 3.36 & * \\
\hline $1 \mathrm{RM}$ bench press & $\mathrm{kg}$ & 1.24 & 0.08 & 1.24 & 0.11 & 0.08 & \\
\hline Bench power & W & 12.80 & 2.19 & 10.95 & 1.80 & 2.54 & \\
\hline Isokinetic chest press $(0.4 \mathrm{~m} /$ & W & 3.52 & 0.43 & 3.39 & 0.33 & 0.89 & \\
\hline Isokinetic chest press $(0.8 \mathrm{~m} /$ & W & 5.79 & 0.71 & 5.41 & 0.57 & 1.62 & \\
\hline Isokinetic chest press $(1.2 \mathrm{~m} /$ & W & 7.19 & 0.95 & 6.38 & 0.65 & 2.76 & \\
\hline
\end{tabular}

ES: effect size ${ }^{*}: \mathrm{P}<0.05$ 


\begin{tabular}{c}
$E S$ \\
\hline 6.28 \\
0.16 \\
4.75 \\
1.67 \\
3.03 \\
5.16 \\
\hline
\end{tabular}




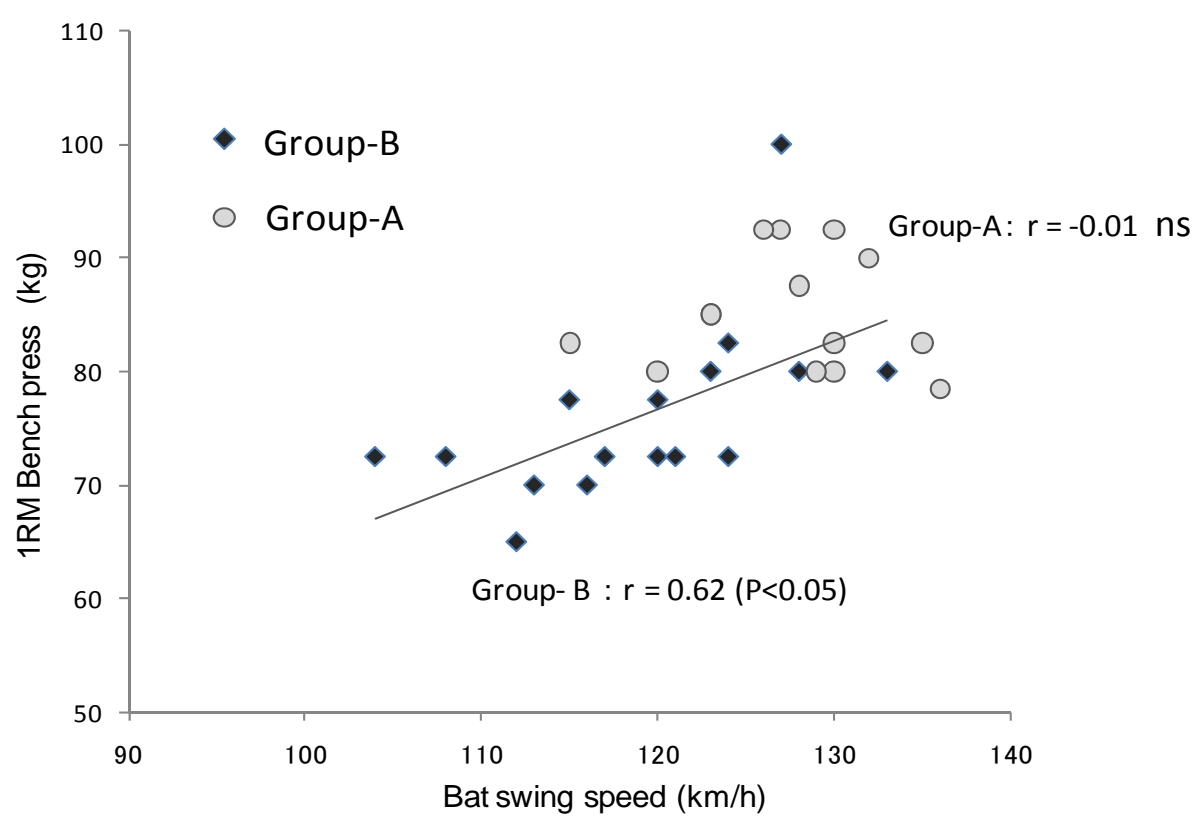

Figure 3 Correlations between bat swing speed and 1RM bench press 